\title{
Improved Storage Stability of Pearl Millet Flour Through Microwave Treatment
}

\author{
Deep N. Yadav • Tanupriya Anand • \\ Jaspreet Kaur • Ashish K. Singh
}

Received: 2 August 2012/ Accepted: 1 November 2012/Published online: 21 November 2012

(C) NAAS (National Academy of Agricultural Sciences) 2012

\begin{abstract}
Due to the high fat content and lipase activity, the pearl millet (Pennisetum typhoides) flour had limited shelflife at ambient conditions. The present study was aimed to inactivate lipase in pearl millet grains through microwave treatment. Microwave heating of pearl millet grains decreased lipase activity significantly $(p<0.05)$ with an increase in moisture level from 12 to $18 \%$ and maximum reduction (92.9\%) was observed at $18 \%$ moisture level for $100 \mathrm{~s}$. Based on lipase inactivation and pasting properties, 80-s duration of microwave exposure at $18 \%$ grain moisture was considered optimum. Significantly $(p<0.05)$ lower change in free fatty acid (FFA, \% oleic acid) value $(20.80-22.25)$ during storage up to 30 days was observed in flour of grains treated for $80 \mathrm{~s}$ at $18 \%$ moisture level as compared to control flour (20.11-32.43). Subjective evaluation of overall acceptability of flour samples showed that microwave-treated flour (18\% moisture level, $80 \mathrm{~s}$ ) was acceptable up to 30 days of storage at ambient conditions, while control flour had unpleasant off odor and bitter taste at the 10th day of storage.
\end{abstract}

Keywords Microwave $\cdot$ Pearl millet flour $\cdot$ Lipase activity $\cdot$ Pasting properties $\cdot$ Storage stability

\section{Introduction}

Pearl millet (Pennisetum typhoides) is one of the most important drought-tolerant crops cultivated mostly in semiarid parts of Africa and Asia and is a major source of energy and proteins for about 500 million people. India continues to be the single largest producer of pearl millet in the world [4]. In general, pearl millet grains contain a higher amount of fat $(7.0-7.9 \%)$ than other cereals, and its flour had poor keeping quality, especially under conditions of moderately high moisture and oxygen exposure $[6,21]$. This is attributed to deterioration of its triglycerides through lipolysis and

D. N. Yadav $(\bowtie) \cdot$ T. Anand · J. Kaur

Food Grains and Oilseeds Processing Division, Central Institute of Post Harvest Engineering and Technology, Ludhiana 141004, Punjab, India

e-mail: dnyadav1977@yahoo.co.in

A. K. Singh

Dairy Technology Division, National Dairy Research Institute,

Karnal 132001, India subsequent oxidation of de-esterified unsaturated fatty acids [14]. Lipase enzyme, which is concentrated in the pericarp, aleurone layer and germ, accounts for the triglyceride hydrolysis in pearl millet grain, resulting in a off odor and taste in the flour and its products [10]. The deterioration of fat triglycerides can be regulated with thermal treatment of flour using dry heat $[3,22]$ or wet heat [12]. Yadav et al. [35] extended the shelf-life of pearl millet flour up to 50 days at ambient conditions by hydrothermal treatment of pearl millet grain.

Microwave heating is based on the transformation of alternating electromagnetic field energy into thermal energy by affecting polar molecules of material. Microwave heat treatment has been widely used to inactivate lipase and lipoxygenase in many agricultural products such as soybean [11], groundnut [24], rapeseed [23], olive oil [9], and oat [13]. It was also found effective in extending the shelf-life of rice bran [8], wheat flour dough [33], and wheat flour [34]. The duration of exposure to microwaves, initial grain moisture content, as well as final temperature of grain controls the lipase and other grain enzymes inactivation and 
subsequently the efficacy of the treatment [11]. Microwave treatment is considered more suitable because of its low operational cost and more precise control during heating as compared to other heat-treatment methods [25]. It is a continuous process that allows large quantities of products to pass in a shorter period of time with no chemical residues left in the food and hence no adverse effects on human beings.

The major objective of this study is to inactivate the lipase activity of pearl millet grains through microwave treatment and thus increase the storage stability of flour at ambient conditions.

\section{Materials and Methods}

Pearl millet grains (var. PHB-2168) grown in the year 2010 were obtained from Punjab Agricultural University, Ludhiana, India. The grains were cleaned using cleaner cum grader (Indosaw, Ambala, India) and stored in gunny bags at $10 \pm 2{ }^{\circ} \mathrm{C}$ until further use. All reagents used for chemical analysis were of analytical grade and procured from Central Drug House, New Delhi, India.

\section{Physical Characteristics}

Grain size was determined using digital Vernier calipers (Model: CD/8" CSX, Mitutoyo, Kawasaki, Japan). Bulk density, the ratio of the mass of grains to its total volume, was determined by filling a predefined container to constant height, striking the top level and then weighing the contents [7]. Thousand grain mass was measured by counting and weighing 1,000 seeds on a digital weighing balance (440-35N, Kern Scales, Bucks, UK) to an accuracy of $0.001 \mathrm{~g} \mathrm{[29].}$

\section{Chemical Analysis}

AACC [1] methods were used to analyze moisture (method 44-19), protein (method 46-12), fat (method 30-25), and ash (method 8-01) contents of whole pearl millet grains. Carbohydrate content was calculated by subtracting the sum of moisture, protein, fat, and ash from 100 [18].

\section{Tempering of Pearl Millet Grains}

Tempering of the grains was done as per the method described by Yadav et al. [33]. Pearl millet sample $(600 \mathrm{~g})$ was placed in a small rotating drum (diameter $=30 \mathrm{~cm}$, length $=40 \mathrm{~cm}$ ) at $25 \pm 2{ }^{\circ} \mathrm{C}$. Moisture content of pearl millet grains was adjusted $(15,18,21$, and $24 \%$, wb) by adding distilled water $(18.4,41,65$, and $92 \mathrm{ml}$, respectively) to tumbling grains from an initial value of $12.4 \pm 0.25 \%$.
After tumbling for $10 \mathrm{~min}$, the moistened grains with 15-24\% moisture were kept in stainless-steel basins at $25{ }^{\circ} \mathrm{C}$ for $1 \mathrm{~h}$. The basins were shaken occasionally for an even moisture distribution.

\section{Microwave Heat Treatment of Pearl Millet Grains}

The tempered sample $(600 \mathrm{~g})$ was placed in a $1,000-\mathrm{ml}$ Borosil glass beaker (filled up to the mark) and treated $(900 \mathrm{~W}, 2,450 \mathrm{MHz})$ in a microwave oven (LG Electronics India Pvt Ltd, Delhi, India, Model MG 607 APR) for 40-100 s. The treated grains were removed from the microwave oven and its temperature was measured using a non-contact infrared thermometer (Model 42510A, Extech Instruments Corporation, Nashua, NH, USA) within $10 \mathrm{~s}$. Treated grains were cooled by spreading in aluminium trays at room temperature. A portion $(25 \mathrm{~g})$ of the cooled pearl millet sample was sealed in a low-density polyethylene (LDPE) $(75 \mu \mathrm{m})$ pouch with minimum head space and used to determine the moisture content. The remaining pearl millet grains were dried to $12 \pm 0.5 \%$ moisture level (wb) at ambient condition, packed in LDPE pouches.

\section{Experimental Plan and Data Analysis}

Experiments were performed using a factorial design consisting of time $(40,60,80$, and $100 \mathrm{~s})$ and moisture (15, 18,21 , and $24 \%$, wb) levels. All the experiments were performed in triplicate. Analysis of variance was calculated as per Snedecor and Cochran [28] using STATISTICA software version-7 (StatSoft Corporation, Tulsa, OK, USA).

\section{Pearling and Milling}

The microwave-treated grains (moisture content $12 \pm$ $0.5 \%$ ) were pearled in batches of $250 \mathrm{~g}$ each for $40 \mathrm{~s}$ in a laboratory-scale rice polisher (Model 6704, Indosaw, Ambala, India). Pearled grains were ground in pulverizer (Lakshmi Industries, Ludhiana, India) and sieved to obtain flour (particle size $\leq 180 \mu \mathrm{m}$ ). Flour samples were packed in LDPE bags and stored at ambient condition for further studies.

\section{Assay for Lipase Activity}

Lipase activity was assayed using a modified method of Vyas and Patel [31] as reported by Nwanguma et al. [20]. A half gram $(0.5 \mathrm{~g})$ of the crude enzyme was added to a reaction mixture prepared by mixing $1 \mathrm{ml}$ of corn oil and $3 \mathrm{ml}$ of $0.1 \mathrm{M}$ phosphate buffer, $\mathrm{pH} 8.0$, in $25-\mathrm{ml}$ flasks. The contents of the flasks were incubated in an orbital shaker for $3 \mathrm{~h}$ at $28 \pm 2{ }^{\circ} \mathrm{C}$. At the end of incubation, $10 \mathrm{ml}$ of neutral 1:1 
ethanol-ether mixture were added. The amount of free fatty acids (FFAs) released was determined by titrating the contents of the flask with $0.1 \mathrm{M} \mathrm{NaOH}$ solution using $0.5 \%$ phenolphthalein as an indicator. Lipase activity is expressed as micromoles of FFAs released per unit time. Blank determinations were carried out by adding enzyme preparations at the end of incubation.

\section{Pasting Properties}

A Rapid Visco-Analyzer (RVA) (RVA-TecMaster, Newport Scientific Pvt. Ltd., Warriewood, Australia) was used to determine pasting properties of the flour. A suspension of $3.5 \mathrm{~g}$ flour (14\% moisture, wb) in $25 \mathrm{ml}$ of distilled water underwent controlled heating and cooling cycle at constant shear. RVA plot of viscosity versus time was used to determine peak viscosity (PV), breakdown (BD), set back (SB), and final viscosity (FV) [1].

\section{Overall Acceptability}

A panel of 30 semi-trained panelists evaluated the flour samples in terms of overall acceptability using a nine-point hedonic scale [15] from liked extremely (9) to disliked extremely (1). Four samples including control were presented at a time to the judges in plates containing a 50-g sample.

\section{Storage Stability}

Samples were packed in LDPE bags $(75 \mu)$ and stored at ambient conditions $\left(15-35^{\circ} \mathrm{C}, 45-85 \% \mathrm{RH}\right)$ for storage studies. The samples were evaluated for changes in peroxide value and FFAs as per AOCS [2] methods and overall acceptability at a 10-day interval.

\section{Results and Discussion}

\section{Pearl Millet Grain Characteristics}

Whole pearl millet grains (PHB-2168 variety) were measured for three major perpendicular dimensions (length, width, and thickness), bulk density and thousand grain mass as $1.91 \pm 0.082 \mathrm{~mm}, 1.69 \pm 0.072 \mathrm{~mm}, 0.92 \pm 0.006 \mathrm{~mm}$, $864 \pm 8.62 \mathrm{~kg} \mathrm{~m}^{-3}, \quad 5.97 \times 10^{-3} \mathrm{~kg}$, respectively. The moisture, protein, fat, ash, and carbohydrates content of the grains were $12.4 \pm 0.25,9.4 \pm 0.13,4.2 \pm 0.23,2.5 \pm 0.1$, and $71.5 \pm 0.52 \%$, respectively. Raw pearl millet grains had $137.5 \pm 0.5 \mu \mathrm{mol} \mathrm{h}{ }^{-1} \mathrm{~g}^{-1}$ lipase activity.

\section{Effect of Microwave Exposure on Lipase Activity}

Figure 1 describes the effect of microwave exposure duration and moisture content on the lipase activity and temperature of pearl millet grains. Lipase activity in the flour samples decreased significantly $(p<0.05)$ with an increase in duration of microwave exposure (0-100 s) at all moisture levels (12-24\%). The grain conditioned at $18 \%$ moisture level had the least lipase activity $\left(7.93 \mu \mathrm{mol} \mathrm{h} \mathrm{h}^{-1} \mathrm{~g}^{-1}\right)$ after 100-s microwave exposure. With subsequent increase/ decrease in grain moisture, the reduction in lipase activity was comparatively lesser as compared to reduction at $18 \%$ moisture level. The maximum lipase activity $\left(69.25 \mu \mathrm{mol} \mathrm{h}^{-1} \mathrm{~g}^{-1}\right)$ was observed in flour of grain at $12 \%$ moisture, followed by $24 \%, 21 \%, 15 \%$, and lowest at $18 \%$ moisture level (Fig. 1). Consequently, the maximum reduction $(92.9 \%)$ in lipase activity was noticed for the flour obtained from the grains treated for $100 \mathrm{~s}$ at $18 \%$ moisture level. The decreased lipase activity of flour may be due to high temperature attained by the sample $\left(107.6^{\circ} \mathrm{C}\right)$ through transformation of microwave energy into thermal energy. Manickavasagan et al. [16, 17] also noted maximum surface temperature as $117.5^{\circ} \mathrm{C}, 97.5^{\circ} \mathrm{C}, 108.8^{\circ} \mathrm{C}$ for moist barley, canola, and wheat, respectively, during microwave treatment. They also reported non-uniform heating pattern during microwave heat treatment. At lower moisture contents (12-15\%), the reduction in lipase activity (38.5\% at $12 \%$ moisture and $87.5 \%$ at $15 \%$ moisture) even at 100-s exposure was not as high as at $18 \%$ moisture level for $80 \mathrm{~s}$. This may be because of the lower generation of heat with lesser availability of polar water molecules. With an increase in grain moisture (21-24\%), the reduction of lipase activity $(84.5 \%$ at $21 \%$ moisture and $70.9 \%$ at $24 \%$ moisture) was again less because of the lower temperature achieved due to evaporative cooling in the grains (Fig. 1). Yadav et al. [33] also observed a similar effect on polyphenol oxidase (PPO) enzyme activity in wheat grains treated with microwave for different durations at different grain moisture levels. Inactivation of lipase enzymes has been correlated to final temperature of the treated grain [11]. Figure 1 clearly depicts the increase in temperature of the samples as affected by duration of microwave exposure. Maximum temperature $\left(107.6^{\circ} \mathrm{C}\right)$ was attained after 100 -s exposure of grains conditioned to $18 \%$ moisture. Bookwalter et al. [5] reported complete inactivation of lipid enzymes in whole proso millets by heat processing with steam-jacketed paddle conveyor having temperatures up to $110{ }^{\circ} \mathrm{C}$. The higher reduction $(96 \%)$ of lipase activity in whole wheat flour during steam heating as compared to the microwave heating (93\% reduction) for similar duration (60 s) was also observed by Rose et al. [26]. Keying et al. [13] also observed lipase inactivation in naked oat kernels 


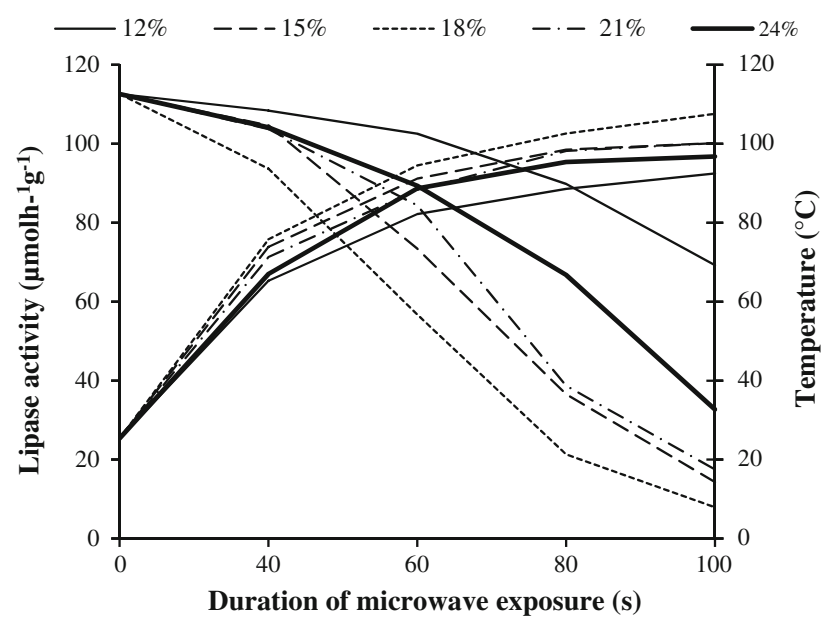

Fig. 1 Effect of microwave exposure on lipase activity and temperature of pearl millet flour. Values are means of triplicate replications $(n=3)$. LSD $(p<0.05) \mathrm{a} \times \mathrm{b}=6.24$; a moisture content; $\mathbf{b}$ duration of microwave exposure

during microwave heating and correlated with temperature and exposure time. Inactivation of lipase by steam and microwave heating is significantly different, because of the different moisture content during heating and not because of the type of heating [23].

\section{Effect of Microwave Treatment on Pasting Properties of Pearl Millet Flour}

Since the least lipase activity was observed in grain samples treated at $18 \%$ moisture, hence flour from these grains was evaluated to explain the starch pasting properties. The pasting properties depend on rigidity of starch potential and amount of amylose leached out in the solution [19]. Figure 2 represents the effect of duration of microwave exposure $(0-100 \mathrm{~s})$ on pasting properties, viz., peak, breakdown, setback, and final viscosities. At 0 -s exposure, the peak viscosity was $1,450 \pm 4.5 \mathrm{cP}$, which decreased significantly $(p<0.05)$ to $779 \pm 5.2 \mathrm{cP}$ with an increase in duration of microwave exposure (100 s). The decrease in viscosity after microwave heat treatment might be due to a breakdown of starch granules. Ward et al. [32] reported re-aggregation of starch granules after microwave treatment. Breakdown viscosity is a measure of the ease with which the swollen granules can be disintegrated and setback indicates increase in viscosity that occurs on cooling of pasted starch. Significant $(p<0.05)$ reduction in breakdown and setback viscosities with increase in duration of microwave exposure was also observed. Breakdown and setback viscosities decreased from 720 and $1,326 \mathrm{cP}(0$-s exposure) to 472 and $655 \mathrm{cP}$ (100-s exposure), respectively. Final viscosity, the ability of material to form viscous paste, decreased significantly $(p<0.05)$ from 2,056 to $962 \mathrm{cP}$ with increase in

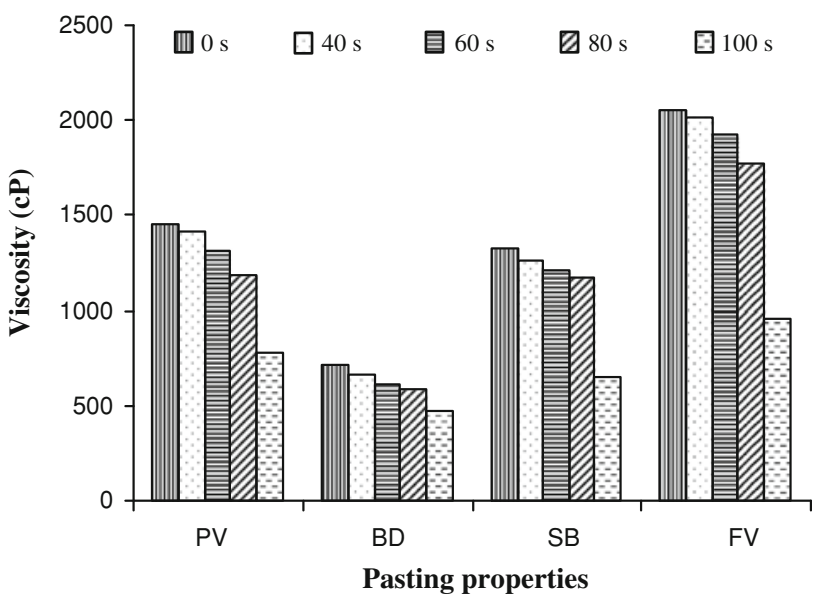

Fig. 2 Effect of duration of microwave exposure on pasting properties in pearl millet flour. $P V$ peak viscosity, $B D$ breakdown viscosity, $S B$ setback viscosity, $F V$ final viscosity. Values are means of triplicate replications $(n=3)$. LSD $(p<0.05)$ for $\mathrm{PV}=104.4$, $\mathrm{BD}=92.5, \mathrm{SB}=74.6, \mathrm{FV}=122.5$

duration of microwave exposure from 0 to $100 \mathrm{~s}$ (Fig. 2). Although all observed pasting properties decreased significantly after 100-s microwave exposure, though the decrease was not significant $(p<0.05)$, up to 80 -s exposure (Fig. 2). Based upon pasting properties and reduction in lipase activity, 80-s microwave exposure time at $18 \%$ moisture was selected as optimum combination.

\section{Storage Study}

Microwave-treated (80 s, $18 \%$ moisture) pearl millet flour and control flour (0 s, $12 \%$ moisture) were studied for changes in peroxide value (PV), free fatty acids (FFA), and sensory quality in terms of overall acceptability (OAA) during storage at ambient conditions $\left(15-35{ }^{\circ} \mathrm{C}, 45-85 \%\right.$ RH) (Fig. 3a-c). Peroxide value increased significantly $(p<0.05)$ in control flour from 11.23 to $28.96 \mathrm{meq} \mathrm{O}_{2} \mathrm{~kg}^{-1}$ fat after 30 days of storage (Fig. 3a). The increasing trend of $\mathrm{PV}$ during storage was in agreement with the observation of Chaudhary and Kapoor [6]. At zero days, PV of microwavetreated flour was 11.55 meq $\mathrm{O}_{2} \mathrm{~kg}^{-1}$ fat, which increased to 2.48 meq $\mathrm{O}_{2} \mathrm{~kg}^{-1}$ fat after 30 days of storage and did not differ significantly $(p<0.05)$ with control. Semwal et al. [27] reported that initially peroxide values increased and thereafter the formation of secondary metabolites take place and thus peroxide values decreased. Non-significant difference in peroxide values of both the samples during storage may be attributed to formation of secondary metabolites. The control samples may contain volatile secondary metabolites of peroxides and thus started to give an off-odor during the initial period of storage. The free fatty acid (FFA) value increased significantly $(p<0.05)$ for both control and microwave-treated flour samples during storage up to 

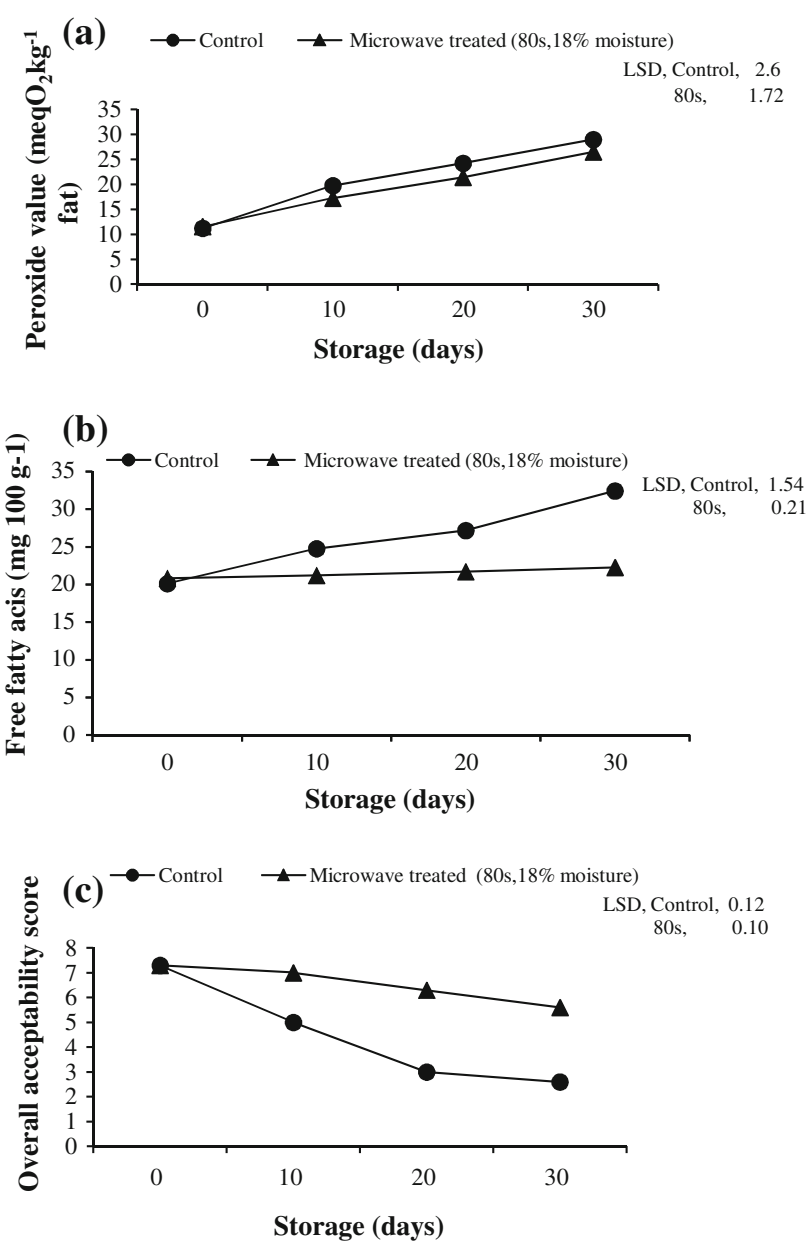

Fig. 3 Effect of storage on peroxide value (a), free fatty acids (b), and overall acceptability (c), in microwave-treated (18\% moisture) pearl millet flour. Values are means of triplicate replications $(n=3)$

30 days (Fig. 3b). However, changes in FFA value $(20.80-22.25 \%)$ for the samples treated for $80 \mathrm{~s}$ at $18 \%$ moisture level was less compared to the control $(20.11-32.43 \%)$. A high FFA value is mainly due to hydrolytic changes associated with the action of lipolytic enzymes [30]. Further, an increase in lipase activity during storage may have lead to a significantly higher FFA value in control than microwave-treated flour.

Sensory evaluation studies revealed that the control sample started to show signs of spoilage at the end of 10th day. Control flour showed rancidity, bitterness, and offflavor because of enzymatic hydrolysis of fat into free fatty acids. The sensory score for control and microwave-treated samples was 5 and 7 , respectively, at the 10th day of storage and differ significantly $(p<0.05)$. Microwavetreated flour was acceptable up to 30 days as a result of lower lipase activity. This is further evident from Fig. 1 as control flour had 112.6 \pm 0.8 , while microwave-treated flour (18\% moisture, $80 \mathrm{~s}$ ) had $21.3 \pm 0.4 \mu \mathrm{mol} \mathrm{h}^{-1} \mathrm{~g}^{-1}$ lipase activity.

\section{Conclusions}

Microwave treatment of pearl millet grains at $18 \%$ moisture for $80 \mathrm{~s}$ resulted in significantly $(p<0.05)$ reduced lipase activity in flour. Pasting properties decreased significantly $(p<0.05)$ with an increase in the duration of microwave exposure. Storage stability studies revealed that microwave-treated flour was acceptable up to 30 days at ambient conditions $\left(15-35{ }^{\circ} \mathrm{C}\right)$ packed in LDPE pouches. As microwave heating is faster and had selective heating ability in comparison to the other conventional heating methods, therefore a continuous microwave system may be used for lipase inactivation in pearl millet. These studies would be beneficial to the researcher, miller, retail seller, as well as consumer, as it would help to store flour usable for a longer time without significant changes in overall quality. It would also encourage utilization of pearl millet grains, which is still untapped despite its numerous nutritious and therapeutic benefits.

\section{References}

1. AACC (2000) Approved methods of the AACC, 10th edn. American Association of Cereal Chemists, St. Paul

2. AOCS (1990) Official methods and recommended practices, 4th edn. American Oil Chemist's Society, Champaign, IL

3. Arora P, Sehgal S, Kawatra A (2002) The role of dry heat treatment in improving the shelf life of pearl millet flour. J Food Sci Technol 16:331-336

4. Basavaraj G, Parthasarathy Rao P, Bhagavatula S, Ahmed W (2010) Availability and utilization of pearl millet in India. J SAT Agric Res 8:1-6

5. Bookwalter GN, Lyle SA, Warner K (1987) Millet processing for improved stability and nutritional quality without functional changes. J Food Sci 52:399-402

6. Chaudhary P, Kapoor AC (1984) Changes in the nutritional value of pearl millet flour during storage. J Sci Food Agric 35: $1219-1224$

7. Deshpande SO, Bal S, Ojha TP (1993) Physical properties of soybean. J Agr Eng Res 56:89-98

8. Faiyaz A, Kalpana P, Suryanarayanaiyer V, Shashikala P (2007) Improved shelf-life of rice bran by domestic heat processing and assessment of its dietary consumption in experimental rats. J Sci Food Agric 87(1):60-67

9. Farag RS, El-Baroty G, El Abd A, Basuny AM (1997) Stabilization of olive oil by microwave heating. Int J Food Sci Nutr 48(6):365-371

10. Galliard T (1999) Rancidity in cereal products. In: Allen JC, Hamilton RJ (eds) Rancidity in foods. Aspen Publishers, Gaithersburg, pp 140-156

11. Jiaxun-Tao RaoR, Liuuzo J (1993) Microwave heating for rice bran stabilization. J Microwave Power Electromag 28(3):156-164

12. Kadlag R, Chavan JK, Kachare DP (1995) Effects of seed treatments and storage on the changes in lipids of pearl millet meal. Plant Food Hum Nutr 47:279-285

13. Keying Q, Changzhong R, Zaigui L (2009) An investigation on pretreatments for inactivation of lipase in naked oat kernels using microwave heating. J Food Eng 95:280-284 
14. Lai CC, Varriano-Marston E (1980) Lipid content and fatty acid composition of free and bound lipids in pearl millet. Cereal Chem 57:271-274

15. Larmond E (1977) Laboratory methods for sensory evaluation of foods. Publication No. 1637, Department of Agriculture, Ottawa, pp $17-22$

16. Manickavasagan A, Jayas DS, White NDG (2006) Non-Uniformity of Surface Temperatures of Grain after Microwave Treatment in an Industrial Microwave Dryer. Dry Technol 24:1559-1567

17. Manickavasagan A, Jayas DS, White NDG (2007) Germination of wheat grains from uneven microwave heating in an industrial microwave dryer. Can Biosyst Eng 49:3.23-3.27

18. Merrill AL, Watt BK (1973) Energy value of foods: basis and derivation. In: Agriculture Handbook No. 74. United States Department of Agriculture, Washington, pp 2-4

19. Morris VJ (1990) Starch gelation and retrogradation. Trends Food Sci Technol 1:2-6

20. Nwanguma BC, Eze MO, Ezengwa OO (1996) Changes in activity of sorghum lipase during malting and mashing. J Inst Brew 102: 39-41

21. Palande KB, Kadlag RY, Kachare DP, Chavan JK (1996) Effect of blanching of pearl millet seeds on nutritional composition and shelf life of its meal. J Food Sci Technol 33(2):153-155

22. Patel KV, Parameswaran M (1992) Effect of heat treatment on lipid degradation in bajra flour. J Food Sci Technol 29:51-52

23. Ponne CT, Moeller AC, Tijskens LMM, Bartels PV, Meijer MTT (1996) Influence of microwave and steam heating on lipase activity and microstructure of rapeseed (Brassica napus). J Agric Food Chem 44(9):2818-2824

24. Ramesh M, Haridas Rao P, Ramadoss CS (1995) Microwave treatment of groundnut (Arachis hypogaea): extractability and quality of oil and its relation to lipase and lipoxygenase activity. LWT-Food Sci Technol 28(1):96-99
25. Ren G, Chen F (1998) Drying of American ginseng (Panax quinquefolium) roots by microwave-hot air combination. J Food Eng 35(4):433-445

26. Rose DJ, Ogden LV, Dunn ML, Pike1 OA (2008) Enhanced lipid stability in whole wheat flour by lipase inactivation and antioxidant retention. Cereal Chem 85(2):218-223

27. Semwal AD, Sharma GK, Arya SS (1999) Pro or anti-oxygenic activity of Tezpat (Cinnamomum tamala) and red chili (Capsicum annum) in sunflower oil. J Sci Food Agric 79:1733-1736

28. Snedecor GW, Cochran WG (1994) Statistical methods, 8th edn. Iowa State University Press, Iowa

29. Sugri I, Nutsugah SK, Yirzagla J (2011) Effect of some seed physical characteristics on viability of pearl millet (Pennisetum glaucum (L.) R. Brown). Res J Seed Sci 4:181-191

30. Thiam AA (1977) Contribution to the study of the biochemical phenomena of millet and sorghum flour determination. In: Tropical Products Institute Conference Papers. Institut Technologie Alimentaire, Dakar, Senegal, pp 69

31. Vyas D, Patel KC (1969) Effect of growth regulators on lipase activity of peanut during germination. J Am Oil Chem Soc 46(3): 176-178

32. Ward KEJ, Hoseney RC, Seib PA (1994) Retrogradation of amylopectin from maize and wheat starches. Cereal Chem 71 : 150-155

33. Yadav DN, Patki PE, Sharma GK, Bawa AS (2008) Effect of microwave heating of wheat grains on the browning of dough and quality of chapatis. Int J Food Sci Technol 43:1217-1225

34. Yadav DN, Patki PE, Sharma GK, Harilal PT, Bawa AS (2009) Studies on the discolouration in whole wheat flour dough. J Food Sci Technol 46:149-152

35. Yadav DN, Kaur J, Anand T, Singh AK (2012) Storage stability and pasting properties of hydrothermally treated pearl millet flour. Int J Food Sci Technol. doi:10.1111/j.1365-2621.2012.03131.x 